Emad F Al-Khalidi

BDS, MSc (Assist Lect)

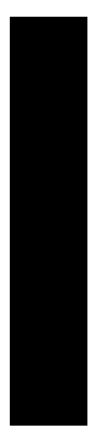

\section{Evaluation of Shear Bond Strength of Ceramic Repair With Resin Composite}

\author{
Department of Conservative Dentistry \\ College of Dentistry, University of Mosul
}

\begin{abstract}
Aim: To evaluate the shear bond strength of intra oral porcelain repair system using different surface treatments when fracture of porcelain with complete metal exposure. Materials and Methods: forty specimens were prepared in form of metal disks $(8 \mathrm{~mm}$ in diameter, this diameter is for each specimen and $15 \mathrm{~mm}$ height) and randomly divided into 4 equal groups. The first two groups were treated with air abrasion. The other groups leaved untouched. Groups I and III were treated with 37\% phosphoric acid while in groups II and IV the surface were treated with $9 \%$ hydrofluoric acid, after that the surfaces of all samples were treated with silane coupling agent then bonding and composite were applied according to the manufacturer instructions. All the samples were stored in a normal physiological saline for 7 days. Then the samples were thermocycled after that Shear bond strength was tested using universal testing machine. Results: The result showed that there was a highly significant difference between groups treated with $\mathrm{Al}_{2} \mathrm{O}_{3}$ with those untreated one, the acid etch material. There was a highly significant difference between samples acid etched using hydrofluoric acid with those etched with phosphoric acid. Conclusion: Air abrasion and the hydrofluoric acid significantly increase the shear bond strength between composite resin and exposed metal of metal ceramic restoration.

Key words: Aluminum oxide, hydrofluoric acid, phosphoric acid.
\end{abstract}

Al-Khalidi EF. Evaluation of Shear Bond Strength of Ceramic Repair With Resin Composite. AlRafidain Dent J. 2007; 7(SpIss): 119S-123S.

Received: 22/10/2007 Sent to Referees: 23/10/2007

Accepted for Publication: 1/11/2007

\section{INTRODUCTION}

Ceramic based restorations are an important part of dentist s armamentarium for durability and esthetic. Ceramic materials with an excellent biocompatibility are widely used to achieve a highly esthetic characteristic in metal ceramic restoration $^{(1)}$. Porcelain fracture is a serious and costly problem for each the patient and the dentist. The problem is more critical if the fracture crown is part of a multiunit restoration. Remarking the crown or fixed partial denture is often in advisable and intra oral repair may be indicated ${ }^{(2)}$.

The ability to bond composite resin to all available restorative materials enables direct repair or correction and reduces the need for complete replacement of restoration. Complete replacement of restoration will be more destructive for the teeth than repair ${ }^{(3)}$

When attempting to repair a fractured ceramo metal restoration it is important to determine the reason for failure. If the failure is due to occlusion or substructure flexure, the repair will probably fail no better than the original restoration. However, if the fracture is due to trauma or technical error during the construction of the original restoration, porcelain repair procedure may be the treatment of choice $^{(2)}$.

The most difficult repair is one in which there is only exposed metal with the minimal or no remaining porcelain. If the crown is single unit, it is usually best to remove it and remake crown rather than attempting a repair. Unfortunately, remaking the retainer (pontic) is not always practical, especially in the case of multiunit fixed partial denture; the retainer can be repaired with composite ${ }^{(4)}$.

New porcelain repair systems showed an excellent adhesion, durability of resin based to the fractured ceramic and exposed metal surface. The clinical success of a repaired ceramic restoration will depend on the quality and durability of the bond between the ceramic and the resin composite. 
The new generations of adhesive systems are multipurpose systems capable of bonding composite to various substrates (enamel, dentin, metal and porcelain) ${ }^{(5)}$.

Shear test was used to evaluate the bond strength between two surfaces using zwick machine ${ }^{(6)}$.

The aim of this study is to evaluate the shear bond strength of intra oral porcelain repair system using different surface treatments when fracture of porcelain with complete metal exposure.

\section{MATERIALS AND METHODS}

\section{Sample preparation}

The samples were fabricated by cutting metal cylinder of $\mathrm{Ni}-\mathrm{Cr}$ alloy (wiron 99 from Bego) $8 \mathrm{~mm}$ diameter, $15 \mathrm{~mm}$ height the cutting was done by using cutting machine with separating disks.

The samples $(8 \mathrm{~mm}$ in diameter and $4 \mathrm{~mm}$ thickness) was placed on a glass slab and fixed by sticky wax, plastic mold was placed on the glass slab around the sam$\mathrm{ple}^{(6)}$.

Self cure acrylic resin was mixed then loaded into the mold so that the sample will be completely imbedded in the acrylic resin totally except its examined surface that faced the glass slab (Figure 1).

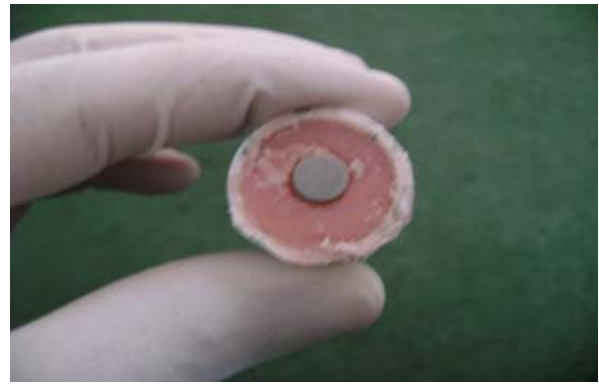

Figure (1): Show metal cylinder imbedded in acrylic with plastic mold.

\section{Sample distribution:}

The 40 blocks were randomly divided into 4 equal groups. Samples of group I and II treated with air abrasion using 50 $\mu \mathrm{m}$ aluminum oxide powder $\left(\mathrm{Al}_{2} \mathrm{O}_{3}\right)$ using air flow device, the nozzle of air flow device was fixed and $5 \mathrm{~mm}$ distance was maintained between the nozzle and the sample surface, each sample was treated for 20 seconds 3 bar pressure.

While, those of groups III and IV were leaved untouched ${ }^{(7,8)}$.
Groups I and III the surface were treated with $37 \%$ phosphoric acid (Vivadent, Liechtenstein) for one minute, while in groups II and IV the surface were treated with $9 \%$ hydrofluoric acid (3M)for one minute. Then all samples washed with copious amount of water for 15 seconds, and dried with oil-free air spray for 10 seconds $^{(9-11)}$.

After that Silane coupling agent (MonoBond-S Vivadent, Liechtenstein) was applied following the manufacturer's directions in all groups and allowed to set for 60 seconds and dried for 10 seconds with oil-free air spray ${ }^{(6)}$.Then Excite bonding agent (Vivadent, Liechtenstein) was applied according to the manufacturer's instructions.

\section{Application of composite}

Using plastic transparent tube of $6 \mathrm{~mm}$ diameter and $2 \mathrm{~mm}$ high (so that the composite will be $2 \mathrm{~mm}$ in thickness), the composite (tetric ceram from Vivadent, Liechtenstein) were applied on the surface cover it with celluloid strip and light cured for 40 seconds $^{(11)}$ (Figure 2).

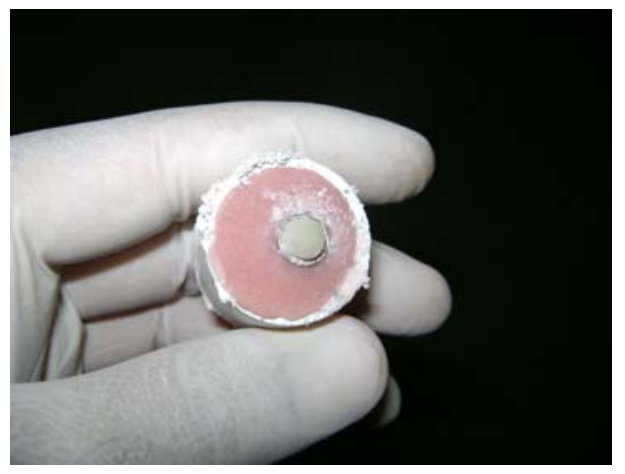

Figure (2): Composite application on metallic cylinder.

\section{Aging and thermo cycling}

All the samples were stored in normal physiological saline for 7 days ${ }^{(12,13)}$. Then the samples were thermo cycled for 200 cycles $^{(2)}$. Thermo cycling was done manually between two water baths the temperature of one bath was maintained at $5^{\circ} \mathrm{C}$ $\pm 2^{\circ} \mathrm{C}$ and the other bath at $55^{\circ} \mathrm{C} \pm 2^{\circ} \mathrm{C}$. The immersion time was for 30 seconds in each bath. ${ }^{(13,14)}$.

\section{Testing procedure:}

Shear bond strength were tested with a universal testing machine using chisel shaped rod, which is specially designed to 
deliver the shearing force, the chisel end of the rod was positioned at the interface between the sample surface and composite.

The specimens were secured tightly in place to ensure that the cylinder was always at $90^{\circ}$ to the vertical plane.

The specimens were loaded until they failed; the forces were recorded in Newton which has been divided by the surface area to obtain shear bond strength calculated in Mpa.

\section{RESULTS}

Statistical analysis of data by using the analysis of variance "ANOVA" revealed that there was highly significant difference between the different groups (Table 1).

Table (1): Analysis of variance of shear bond strength for porcelain repair with four different surface treatment

\begin{tabular}{llllll}
\hline Source of variance & df & Sum of square & Mean of square & F-valu & $p$-valu \\
\hline Between groups & 3 & 245.345 & 81.782 & 122.81 & 0.000 \\
Error & 36 & 23.973 & 0.666 & & \\
\hline Total & 39 & 269.318 & & & \\
\hline df: Degree of freedom & & & &
\end{tabular}

Bar chart showed that the mean value of shear bond strength in Mpa for all groups (Figure 3).

Further investigation using student $\mathrm{t}-$ test showed that there were highly significant differences between groups treated with $\mathrm{Al}_{2} \mathrm{O}_{3}$ and untreated groups.

Also student $\mathrm{t}$-test showed highly significant differences between groups acid etched with hydrofluoric acid with corresponding groups acid etched using phosphoric acid (Table 2).

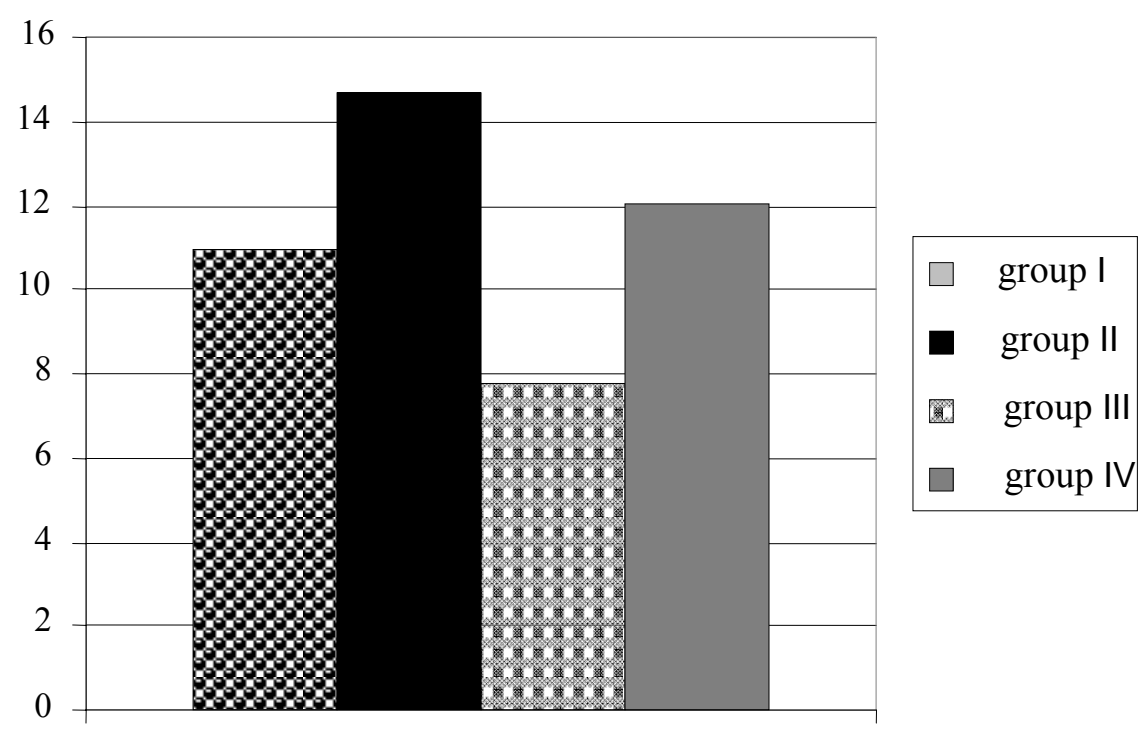

mean

Figure (3): Bar chart show the mean value of shear bond strength in Mpa for all groups. I: Group one that treated with air abrasion using $50 \mu \mathrm{m} \quad \mathrm{Al}_{2} \mathrm{O}_{3}$ and $37 \%$ phosphoric acid; II: Group two that treated with air abrasion using $50 \mu \mathrm{m} \quad \mathrm{Al}_{2} \mathrm{O}_{3}$ and $9 \%$ hydrofluoric acid; III: Group three treated with $37 \%$ phosphoric acid only; IV: Group four treated with $9 \%$ hydrofluoric acid only 
Table (2): T-Test of four different surface treatment of shear bond strength of porcelain repair.

\begin{tabular}{cccccc} 
Groups & Mean of different tested group & t-value & P-value & Significancy \\
\hline I\&III & 10.960 & 7.754 & 8.68 & 0.000 & Significance \\
II\&IV & 14.661 & 12.049 & 7.25 & 0.000 & Significance \\
I\&II & 10.960 & 14.661 & 9.08 & 0.000 & Significance \\
III\&IV & 7.754 & 12.049 & 13.58 & 0.000 & Significance \\
\hline
\end{tabular}

I: Group one that treated with air abrasion using $50 \mu \mathrm{m} \quad \mathrm{Al}_{2} \mathrm{O}_{3}$ and $37 \%$ phosphoric acid; II: Group two that treated with air abrasion using $50 \mu \mathrm{m} \quad \mathrm{Al}_{2} \mathrm{O}_{3}$ and $9 \%$ hydrofluoric acid; III: Group three treated with 37\% phosphoric acid only; IV: Group four treated with $9 \%$ hydrofluoric acid only

\section{DISCUSSION}

\section{Effect of air abrasion:}

The results of this study showed that there were highly significant differences in shear bond strength between groups treated with $\mathrm{Al}_{2} \mathrm{O}_{3}$ and their corresponding untreated groups. This may be due to that the $\mathrm{Al}_{2} \mathrm{O}_{3}$ increase the surface area and the particles incorporated inside the metal surface thereby increasing surface energy and bonding. This agreed with the result of Chung and Hwang ${ }^{(15)}$, they found that air abrasion significantly increase the bond between ceramic and composite.

Kussano et al., ${ }^{(16)}$ reported that creation of surface roughness such as grooves or undercuts on the porcelain surface with coarse diamond burs and discs enhance the bond to the composite.

\section{The effect of Type of acid}

Etching procedures are used to facilitate the bonding between the metal surface and the composite resin, because it creates a porous surface this porosity lead to increase the retentive bond between the resin and metal. In this study the hydrofluoric acid produce high shear bond strength than the groups treated with phosphoric acid, this agreed with the Della Bona ${ }^{(9)}$ who reported that hydrofluoric acid etching produce aggressive effect on the surface of ceramic.

More research is needed to see the effect of hydrofluoric acid on the surface of different types of metal (precious Inon precious) which used in the metal ceramic restoration.

\section{CONCLUSION}

Under the condition of this study the following conclusion could be drown:

1. Air abrasion and the hydrofluoric acid significantly increase the shear bond strength between composite resin and exposed metal of metal ceramic restoration.

2. The time of acid application is enough for metal treatment.

\section{REFERENCES}

1. Kappert HF. Modern metal ceramic system. Dent News. 1998; 11: 29-40.

2. Aschheim KW, Dale BG. Esthetic Dentistry. A Clinical Approach to Technique and Materials. $2^{\text {nd }}$ ed., Mosby Co., 2001; ch: 3,4,7.

3. Trautmann G, Gutmann JL, Nunn ME, Witherspoon DE, Shulman JD (2000). Restoring teeth that are endodontically treated through existing crowns. Part II: Survey of restorative materials commonly used. Quintessence Int. 2000;10: 719-28. (Abstract)

4. Haselton D.R, Diaz-Arnold Am, Dunne JT. Shear bond strength of 2 intra oral porcelin repair systems to porcelian or metal substrates. $J$ prosthet dent. 2001; 86: 526-531.

5. Kupiec KA, Wuertz KM, Barkameier WW. Evaluation of porcelain surface treatment and agents for composite to porcelain repair. $J$ Prosthet Dent. 1996; 76: 119-124..

6. Al-Ja'afari KA. Evaluation of the shear bond strength of the intraoral porcelain repair system with different surface treatment. MSc thesis. College of Dentistry. University of Baghdad.2002

7. Al-Ani ZY (2002). Evaluation of the 
microleakage of different restorative materials used to repair a perforation in a metal casting (Nickel-Chromium). MSc thesis. College of Dentistry. University of Baghdad. 2002.

8. Lacy AM, Laluz J, Watanabe LG, Dellinges $M$. Effect of porcelain surface treatment on the bond to composite. $J$ Prosthet Dent. 1998; 60: 288-291.

9. Della-Bona A. Characterizing ceramics and the interfacial adhesion to resin: the relationship of surface treatment, bond strength interfacial toughness and fractography. $J$ appl oral sci. 2005; 13:101-109.

10. Galindo DF, Ercoli C, Graser GN, Tallents RH, Moss ME. Effect of soldering on metal-porcelain bond strength in repaired porcelain fused to metal castings. J Prosthet Dent. 2001; 85: 88-94.

11. Aida M, Hayakawa T, Mizukawa K (1995). Adhesion of composite to porcelain with various surface conditions. J Prosthet Dent 73: 464-70.

12. Williams PT, Schramke D, Stockton
L. Comparison of two methods of measuring dye penetration in restoration microleakage studies. Oper Dent.2002; 27: 628-635.

13. Staninec M, Mochizuki A, Tanizaki K, Fukada K, Tsuchitani Y. Interfacial space, marginal leakage, and enamel cracks around composite resins. Oper Dent. 1985; 11: 14-24.

14. Hakimeh S, Vaidyanathan J, Houpt ML, Vaidyanathan TK, Vonhagen S. Microleakage of compomer $\mathrm{Cl} \mathrm{V}$ restorations: effect of load cycling, thermal cycling, and cavity shape differences. J Prosthet Dent. 2002. 83(3): 194-203.

15. Chung KH, Hwang YC. Bonding strengths of porcelain repair systems with various surface treatments. $J$ Prosthet Dent.1997; 78: 267-274.

16. Kussano CM, Bonfant G, Batista JG and Pinto JHN. Evaluation of shear bond strength of composite to porcelain according to surface treatment. Braz Dent J. 2003; 14:132-135. 